\title{
Implementation of 5S practices: A review
}

\author{
Jagtar Singh $^{\mathrm{a}}$, Vikas Rastogi ${ }^{\mathrm{b}}$ and Richa Sharma ${ }^{\mathrm{c}^{*}}$
}

${ }^{a}$ Mechanical Engineering Department, SLIET Longowal-148106, Distt. Sangrur, Punjab, India

${ }^{b}$ Department of Mechanical \&Production Engineering, Delhi Technological University Delhi-1 10042, India

${ }^{c}$ PhD. Research Scholar, Mechanical Engineering Department, SLIET Longowal-148106, Sangrur, Punjab, India

\section{H R O N I C L E \\ A B S T R A C T}

Article history:

Received December 10, 2013

Received in revised format

16 March 2014

Accepted April 292014

Available online

May 22014

Keywords:

$5 S$

Efficiency

Housekeeping

Total Productive Maintenance

Total Quality Management Availability
$5 \mathrm{~S}$ is a systematic technique used by organizations come from five Japanese words; Seiri (Sort), Seiton (Set in order), Seiso (Shine), Seiketsu(standardize) and Shitsuke (sustain). This system helps to organize a workplace for efficiency and decrease non value added activities and optimize quality and productivity through monitoring an organized environment. This paper aims to review previous studies about benefits of $5 \mathrm{~S}$ Implementation and its efficiency in organizations. The results show that $5 \mathrm{~S}$ is an effective tool for improvement of organizational performance, regardless of organization type, size, its production or its service. Consequently, $5 \mathrm{~S}$ technique would strongly support the objectives of organization to achieve continuous improvement in performance and productivity.

\section{Introduction}

Nowadays, in this dynamic and technological world, the secret of surviving for any kind of organization is to be competitive and pioneer in its products or services. Normally, this improvement has been achieved through implementation of best practices, which are chosen to meet a particular objective. With increasing of the competition in the world, two major challenges are in front of organizations' managers: First, in this competitive environment, managers have to make the best decisions and choose the best methods to achieve their objectives and not to lose very finite opportunities. Second, lack of knowledge is one of the most important problems of managers about familiarity with an appropriate method to improve the performance of organization, successfully. In addition, the quality of performance also is vital to be evaluated and recognized. Such an evaluation can help managers identify the improvement of performance. $5 \mathrm{~S}$ is a way to improve the performance and to organize the whole system, which has been used first time by Japanese. It comes from five Japanese words start with S, which is translated into English words to give the best explanation for them.

* Corresponding author. Tel: +8130857467

E-mail address: richasahnivirgo@gmail.com (R. Sharma)

(C) 2014 Growing Science Ltd. All rights reserved. doi: $10.5267 /$ j.uscm.2014.5.002 


\section{5S technique}

The $5 \mathrm{~S}$ concept comes from Japan. The original purpose of the $5 \mathrm{~S}$ is to make the workplace orderly to improve safety and efficiency, reducing the product defects rate. It is expressed by five Japanese words that express cleaning and order at the company and accepting this as work discipline as shown in Fig. 1. These words are (Patra et al., 2005; Mora, 2007):

i.) Seiri: Sort

ii.) Seiton: Set in Order/Straighten

iii.) Seiso: Shine/Sweep

iv.) Seiketsu: Standardize

v.) Shitsuke: Sustain/Self-discipline

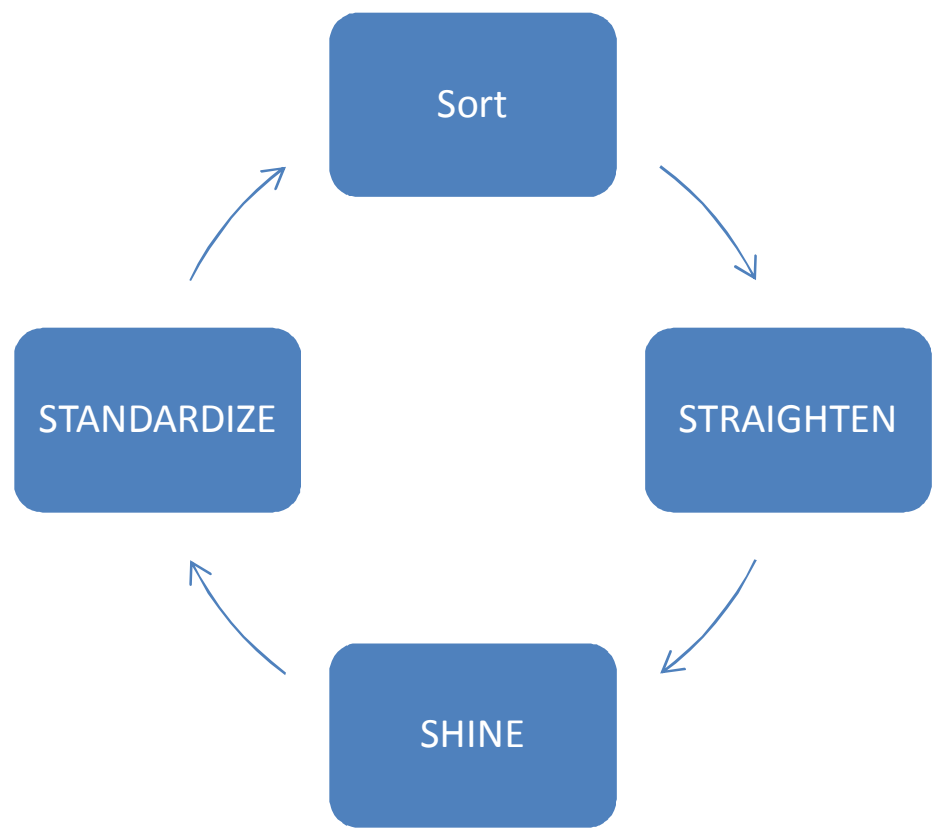

Fig. 1. 5S Technique

\subsection{Seiri (Sort)}

Sorting necessary and unnecessary materials is called "sort". The arrangement used for keeping each material in the company at correct place is named as Sort (Mora, 2007). The defective or rarely used material and equipment in the company cause the demolishment of the workplace's order and decrease in the work efficiency (Sancoban, 2006). Therefore, the necessary and unnecessary materials available in the workplace should be sorted and classified. In order to improve the availability of the working machine and hardware; some workstations such as the machines, tools, hand machines, materials to be used etc. should be kept available in an order and at places where can be easily accessed (Celebi, 1997; Kocalam, 1999). For this reason, when this first basic principle is well applied, the problems and complaints through the work flow will decrease and the communication between the personnel will be simplified. In addition to this, since serious savings will be obtained in the size of the required working environment, important drops will be observed in the operation cost (Sarıcoban, 2006). 


\subsection{Seiton (Set in Order)}

According to this purpose, a localization order is designed for easily accessing to the necessary materials at required times and the materials are put their own places again after utilization (Patra et al., 2005). As a result of the arrangement performed at the work stations (machines, tools, hand tools, materials to be used, etc.), these should be kept at a place where can be accessed easily due to the case of requirement (Kocalan, 1999). The place where the operation is actually realized, material transition paths and the storage method are the points that should be considered in this step. Some points that can be controlled during regulation can be summarized as following (Celebi, 1997):

i.) Stock areas should be used at top level. Solutions such as a shelf order in proportion to the height of the classified material and drawers instead of big sized cupboards and boxes can gain efficiency in terms of stocking.

ii.) In cases where "First in first out" principle is used, it should be avoided that stocking is deep

iii.) The stock areas, shelf and drawers as well as materials should be labeled.

iv.) In case if the dimension and kind of the product change, then special vehicles may be used in machine adjustments.

\subsection{Seiso (Shine/Sweep)}

In order to realize effective tasks, it is essential to create a clean and regular working and living environment (Patra et al., 2005). This is because dust, dirt and wastes are the source of untidiness, indiscipline, inefficiency, faulty production and work accidents (Anon, 2007). We can handle cleaning practices as a two stepped approach; "general cleaning of workplace and availability of dirtiness sources" and "machine, hardware, tool cleanliness" referred as detailed cleaning (Celebi, 1997). In case of detailed cleaning, some advantages can be obtained. These can be summarized as following (Karabulut, 1999):

i.) Dirt and dust causes bad operation, corrosion and early demolishment of machine and its components. Therefore, dirt and dust sources are removed.

ii.) As a result of making the workplace more proper to the working conditions, the morale of the personnel improves.

iii.) The abnormal cases such as lubricant leakage, wastes, etc. are recognized immediately.

iv.) As a result of psychological impact, the reactions and performances of the personnel get better.

v.) Through providing a safer working environment, the danger contained works decrease.

In order to realize shining through an effective system, the names of the personnel who are responsible from the cleaning of each zone, each department and each point of the factory should be clearly determined and written at the proper places. The shining time should be very short in order to obtain effective utilization. The best times for cleaning are the beginning of shift, end of shift or after meal. All personnel should be well trained about cleaning and participate in cleaning.

\subsection{Seiketsu (Standardize)}

Following the application of first $3 \mathrm{~S}$ principles, the necessary systems are formed in order to maintain the continuance of these good practices at the workplace. In order to do this, these activities should be written according to the procedures and the memorization of these procedures by the personnel as well as the functionality of the rules should be obtained. Providing the visual control that will enable the revealing of the problems that may negatively affect the conducted cleaning and the order is very 
important here. The methods which can be recognized by anyone at the workplace, not only by the relevant person, should be developed. It will be appropriate to write down performance monitoring labels, control lists, tables and some procedure for visual understanding on TPM board that will be formed in order to control the activities. Following the visual control, the following activities are realized in standardize (Celebi, 1997; Kocaalan, 1999):

i.) Allocation of workplace in terms of area or machine based regions.

ii.) Determination of representatives for each region.

iii.) Identification of points required to be controlled in each region (formation of cleaning-order lists).

iv.) Removal of negativities recognized as a result of controls.

For full application and development of the standards, the participation of all personnel is required. Therefore, standardization means to make correct attitude and behaviors as daily habits and assure their full application in order to get over the handicaps in the first three basic principles.

\subsection{Shitsuke (Sustain/Self discipline)}

The last step of $5 \mathrm{~S}$ program covers the improvement of the methods directed to the adaptation of $5 \mathrm{~S}$ as habit by all personnel. The task here is undertaken by the leader directors. The directors should explain the importance of $5 \mathrm{~S}$ to the personnel through various trainings and the knowledge of the personnel about $5 \mathrm{~S}$ should be kept. Updated through the $5 \mathrm{~S}$ boards to be formed at the workplace. Through various campaigns with easy participation, the dissemination of $5 \mathrm{~S}$ should be targeted (Celebi, 1997). The objectives of these studies can be summarized as following (Karabulut, 1999):

i.) Formation of a disciplined company.

ii.) Removing small faults through the aid of cleaning.

iii.) Providing the execution of visual control.

iv.) Granting the responsibility of the machine to the worker

v.) Providing the performance of protective activities.

vi.) And granting the responsibility of the workplace to the personnel.

\section{Review on $5 S$}

$5 \mathrm{~S}$ is a useful method for founding an organization and spread out a design and can improve communication and help employees to develop their characteristics to decrease downtime, lead time, inventory, defect and associated cost (Van Patten, 2006).. Result of the study indicates that 5S technique is an effective way to improve health and safety standards, environmental performance and housekeeping (Rahman, et al., 2010). 5S is a method for development of companies, change and training. Hirano in 1995 regards $5 \mathrm{~S}$ as an industrial practice that distinguishes an organization from the others (Osada, 1991). According to the Japanese organizations 5S have two components, a high level of management and organizational system with complexity meaning and it translates to perfect performance and the other one is management provision tools position (Gapp et al., 2008). Even though the 5S housekeeping program aids production (Eckhardt, 2001) but the 5S technique is one of the most known in industrial and business environment and there are few proofs about its adoption in organizations (Bayo-Moriones et al., 2010). Other studies still accept 5S as a method of housekeeping (Eckhardt, 2001; Becker, 2001; Ahmed \& Hassan, 2003; Chin \& Pun, 2002). However, there are other ideas that believe 5S is a supportive way for Lean and TQM (Kumar et al., 2006).

From the quality management point of view, order and cleanliness have been considered as a part for continuous improvement (Yusof \& Aspinwall, 2001) and a point to start continuous improvement and more advancement in organizations. $5 \mathrm{~S}$ can link with total productive maintenance (TPM) (Ahuja \& 
Khamba, 2008) and Japanese management approaches such as TPM, JIT and TQM (Gapp et al., 2008). Generally, the success of 5S implementation depends on organizational characteristics (Sousa $\&$ Voss, 2008) as this mentioned in many surveys (Bayo Moriones et al., 2008). Survey of one factory in Iran supports pervious findings in this field and indicates that $5 \mathrm{~S}$ execution provides better condition for implementation of TPM (Moradi et al., 2011). As it is mentioned in several studies, the $5 \mathrm{~S}$ method is recorded as a way for improving health and safety standard and performance in a holistic operation with high level of efficiency (Khamis, et al., 2009) and also helps improving data management system in factories (Ananthanarayanan, 2006). On the other hand, there is correlation between the 5S and TQM, which further approve the role of 5S as a training tool for TQM and also the need for a sound approach towards TQM (Ho et al., 1995). There is a considerable decreasing in the rate of injuries in the companies where the objective is improving safety through the $5 \mathrm{~S}$ practice. (Ansari \& Modarress, 1997).

The 5S practice is beneficial for every organization, because it helps everyone having a better life (da Silveira, 2006). In fact, many successful organizations in the world have already included some aspects of the $5 \mathrm{~S}$ in their daily activities without complete awareness of its benefits (Ho, S.K.M; 1999). Indian companies are informed about the quality improvement requirements, although disciplined approach is not yet in place and improvement efforts are not enough to remove weaknesses specially in term of quality (Khanna, 2009). More investigation is needed on implementation of the $5 \mathrm{~S}$ as an improving tools in a business section and some items like company size and structure could affect application of the 5S and its effectiveness (Eocha, 2000). Actually, there is not much difference between ISO 9001 requirements for implementing quality management system and $5 \mathrm{~S}$ rules which can be joined by extending the ISO 9000 pattern to combine related $5 \mathrm{~S}$ rules (Pheng, 2001). This system is beneficial for any workplace to make high quality products and services (Sui PPheng \& Khoo, 2001).

$5 \mathrm{~S}$ is applied in most of the factories in manufacturing sections with priority compare to other sections with different ways which can be attributed to the maturity of the $5 \mathrm{~S}$ program (Warwood \& Knowles, 2004). Mixing lean manufacturing initiatives through 5S with safety yield safety results that are well aligned with the rest of the organization (Becker, 2001). Ho in 1998 says the 5S practice is the key to productivity and quality and he also determines the $5 \mathrm{~S}$ audit methods and reports to adapt and adopt to the business environment via the training sessions and case studies carried out by the industry department. Furthermore, he realized that the $5 \mathrm{~S}$ practice is very beneficial due to its helps for everybody to have a better lifestyle in the organization (Ho, 1998).

Hamzah and Ho (1994) believe that the 5S is not new and we have had it for long time. We need the $5 \mathrm{~S}$ at our workplace because many people do their things without thinking about it. In addition, $5 \mathrm{~S}$ can be a reflection of our behavior. If we have a consideration to $5 \mathrm{~S}$, the majority of our routine problems that we face in everyday works could be solved. Hubbard (1999) showed that orderliness which is one of the five pillars of the visual workplace, intends to eliminate three types of waste: searching waste, difficulty-of-use waste, and the waste of returning items to their proper place. Ho (1997) presents Audit Worksheet for 5S, which is a practical tool for 5S implementation. He also believes Japanese $5 \mathrm{~S}$ fundamentals that must be used for continuous quality improvement.

A useful environmental tool for organization management is $5 \mathrm{~S}$, which comes from lean manufacturing process. The $5 \mathrm{~S}$ practice simplifies the workplace and maintenance system's procedures, decrease waste and non-value added activities. It also improves quality, efficiency and safety. It is the most effective tool of control, which at least reduce or totally avoid different types of pollutions (Nilipour \& Jamshidian, 2005). 


\section{Conclusion}

The most important barrier for implementation of $5 \mathrm{~S}$ effectively is poor communication. Techniques of communication and their efficiency are seldom evaluated and communication faults rarely addressed in an industrial workplace. Poor communication can cause wasting resources, time and money, and lowering moral amongst employees. The results of evolving communication systems in an uncontrolled fashion in industries or business could be confusing and complex. There must be an applicable way for using $5 \mathrm{~S}$ as an improvement tool for communication system. The surveys indicate that there are difficulties in the effective $5 \mathrm{~S}$ implementation. Another significant barrier is the space between managerial level and shop floor employees and the poor training and awareness of 5S. Since some critical decisions of $5 \mathrm{~S}$ activities, including time and budget performance must approve and support by management, therefore more cooperation is recommended during implementation period (Gapp et al., 2008).

It is concluded that $5 \mathrm{~S}$ key of success is training. $5 \mathrm{~S}$ implementation is not possible without proper training and employees are not capable to actively standardize the 5S (Ho, S.K.M; 1999). Organization should pay attention to this fact that resistance to change is one issue, which will be occurring during $5 \mathrm{~S}$ implementation. Therefore, it is believed that continuous training is the key applying to change the organization culture, and assessment should focus on improvement and progress regarding all input from the organization until complete establishment of $5 \mathrm{~S}$ system (Nilipour \& Jamshidian, 2005).

It is obvious that the target of $5 \mathrm{~S}$ application is vast and diverse and when effectively implemented, the business improvement can be surprising. However, the total benefits of $5 \mathrm{~S}$ cannot be imagined in industries and business, until the barriers associated, fully understood, addressed and removed.

\section{References}

Ahuja, I. P. S., \& Khamba, J. S. (2008). Total productive maintenance: literature review and directions. International Journal of Quality \& Reliability Management,25(7), 709-756.

Ahmed, S., \& Hassan, M. (2003). Survey and case investigations on application of quality management tools and techniques in SMIs. International Journal of Quality \& Reliability Management, 20(7), 795-826.

Ananthanarayanan, K. R. M. (2006). Application of 5S Management System in NDE Laboratory. In National Seminar on Non-Destructive Evaluation.

Ansari, A., \& Modarress, B. (1997). World-class strategies for safety: a Boeing approach. International Journal of Operations \& Production Management, 17(4), 389-398.

Anon, (2007). 5S Management. http://vdb.gib.govtr/edirnevdb/sunumlar/5S Sunum/5Sy. html.

Bayo-Moriones, A., Bello-Pintado, A., \& De Cerio, J. M. D. (2010). 5S use in manufacturing plants: contextual factors and impact on operating performance.International Journal of Quality \& Reliability Management, 27(2), 217-230.

Bayo-Moriones, A., Bello-Pintado, A., \& Merino-Díaz-de-Cerio, J. (2008). The role of organizational context and infrastructure practices in JIT implementation. International Journal of Operations \& Production Management, 28(11), 1042-1066.

Becker, J.E. (2001). Implementing 5S to promote safety \& housekeeping. Professional Safety, 46(8), 29-31.

Celebi, H. T. (1997). $5 S$ and total productive maintenance with total quality perspective (Doctoral dissertation, M. Sc. Thesis, Istanbul University, Institute of Science, Istanbul, Turkey).

Chin, K. S., \& Pun, K. F. (2002). A proposed framework for implementing TQM in Chinese organizations. International Journal of Quality \& Reliability Management, 19(3), 272-294.

da Silveira, G. J. (2006). Effects of simplicity and discipline on operational flexibility: an empirical reexamination of the rigid flexibility model. Journal of Operations Management, 24(6), 932-947. 
Eckhardt, B. (2001). The 5S housekeeping program aids production. Concrete products, 104(11), 56.

Gapp, R., Fisher, R., \& Kobayashi, K. (2008). Implementing 5S within a Japanese context: an integrated management system. Management Decision,46(4), 565-579.

Hamzah, A., \& Ho, S. (1994). TQM training for small and medium industries in Malaysia. Training for Quality, 2(2), 27-35.

Ho, S. K., Cicmil, S., \& Fung, C. K. (1995). The Japanese 5-S practice and TQM training. Training for Quality, 3(4), 19-24.

Ho, S. K. (1997). Workplace learning: the 5-S way. Journal of Workplace Learning, 9(6), 185-191.

Ho, S.K.M. (1998). 5S practice: a new tool for industrial management. Industrial Management \& Data Systems, 98(2), 55-62.

Ho, S. K. (1999). Japanese 5-S-where TQM begins. The TQM Magazine, 11(5), 311-321.

Hubbard, R. (1999). Case study on the 5S program: the five pillars of the visual workplace. Hospital materiel management quarterly, 20(4), 24-28.

Karabulut, A. (1999). Total productive maintenance management" M.Sc. Thesis, Anadolu University, Institute of Social Sciences, Eskisehir, Turkey.

Khanna, V. K. (2009). 5 "S" and TQM status in Indian organizations. The TQM Journal, 21(5), 486501.

Khamis, N., Abrahman, M. N., Jamaludin, K. R., Ismail, A. R., Ghani, J. A., \& Zulkifli, R. (2009). Development of 5S practice checklist for manufacturing industry. In Proceedings of the World Congress on Engineering (Vol. 1, pp. 978-988).

Kocaalan, M.L. (1999). Improving and increasing machine performance loy using total productive maintenance (TPM) approach. M.Sc. Thesis, Gazi University, Institute of Science and Technology, Ankara, Turkey.

Kumar, M., Antony, J., Singh, R. K., Tiwari, M. K., \& Perry, D. (2006). Implementing the Lean Sigma framework in an Indian SME: a case study. Production Planning and Control, 17(4), 407423.

Mora, E. (2007). Essential in The Lean Manufacturing Structure: The "5S" Philosoph. http://www.tpmonline.com/papakaizen.articls_on_lean_manufacturingstrategies $/ 5 \mathrm{~s} . \mathrm{htm}$.

Moradi, M., Abdollahzadeh, M. R., \& Vakili, A. (2011, September). Effects of implementing 5S on total productive maintenance: a case in Iran. In Quality and Reliability (ICQR), 2011 IEEE International Conference on (pp. 41-45). IEEE.

Nilipour, A., \& Jamshidian, M. (2005). 5S As an Environmental Organization Management Tool. In Benefits and Barriers. International Management Conference.

O'hEocha, M. (2000). A study of the influence of company culture, communications and employee attitudes on the use of $5 \mathrm{Ss}$ for environmental management at Cooke Brothers Ltd. The TQM Magazine, 12(5), 321-330.

Osada, T. (1991). The 5S's: five keys to a total quality environment” Asian Productivity Organization Tokyo.

Patra, N. K., Tripathy, J. K., \& Choudhary, B. K. (2005). Implementing the office total productive maintenance ("Office TPM") program: a library case study. Library Review, 54(7), 415-424.

Pheng, L.S. (2001). Towards TQM - Integrating Japanese 5S principles with ISO 9001: 2000 requirements. The TQM Magazine, 13(5), 334-341.

Rahman, M. N., Khamis, N. K., Zain, R. M., Deros, B. M., \& Mahmood, W. H. (2010). Implementation of $5 \mathrm{~S}$ practices in the manufacturing companies: A case study. American Journal of Applied Sciences, 7(8), 1182-1189.

Saricoban, E. (2006). The importance of $5 \mathrm{~S}$ in total productive maintenance activities and an application of 5S. Non-Thesis M.Sc. Project, Dokuz Eylül University, Institute of Social Sciences, Izmir, Turkey.

Sousa, R., \& Voss, C. A. (2008). Contingency research in operations management practices. Journal of Operations Management, 26(6), 697-713.

Sui-PPheng, L., \& Khoo, S. D. (2001). Team performance management: enhancement through Japanese 5-S principles. Team Performance Management, 7(7/8), 105-111. 
Van Patten, J. (2006). A second look at 5S. Quality progress, 39(10), 55.

Warwood, S. J., \& Knowles, G. (2004). An investigation into Japanese 5-S practice in UK industry. The TQM Magazine, 16(5), 347-353.

Yusof, S. R. M., \& Aspinwall, E. (2001). Case studies on the implementation of TQM in the UK automotive SMEs. International Journal of Quality \& Reliability Management, 18(7), 722-744. 